\title{
Partnerships in Full-Day Kindergarten Classrooms: Early Childhood Educators and Kindergarten Teachers Working Together
}

\author{
Kathryn Underwood, Aurelia Di Santo, Angela Valeo, and Rachel Langford
}

\begin{abstract}
The authors are associate professors in the School of Early Childhood Studies, Ryerson University. Kathryn Underwood's research interests include early childhood social policy, disability as identity, and inclusive practice in early childhood education and care settings. Aurelia Di Santo researches children's rights, children's participation in research and in their early learning programs, transitions to school, and play-based learning. Angela Valeo has many years of elementary school teaching experience. Her areas of specialization and research concern the inclusion of students with disabilities in preschools and elementary school classrooms. The research interests of Rachel Langford, who is the director of the School of Early Childhood Studies, include early childhood teachers' work and history, the Canadian childcare movement, and professional preparation.
\end{abstract}

This study examines the relationship between teachers and early childhood educators in full-day kindergarten classrooms in one school board in Ontario. The study uses the theoretical framework of co-teaching models developed in special education to analyze the range of approaches used by the educator teams. Findings indicate that the teams primarily engage in a one teach/one assist approach, but they also describe some examples of other co-teaching approaches that are possible in these classrooms. The study concludes that support for the expansion of the co-teaching repertoire could provide a mechanism for integrating the expertise of both educators in full-day kindergarten classes and maximizing the efficacy of this social policy direction. Implications for educators and administrators are addressed.
Full-day early learning programs, where children attend kindergarten every day for a full day, have been gaining support in recent years in Canada (e.g., British Columbia, New Brunswick, Nova Scotia, Ontario, Prince Edward Island, Quebec, Newfoundland and Labrador) and around the world (e.g., New Zealand, Australia; Early Childhood Learning Agency, 2009; Flanagan, 2011; Ryan \& Date, 2014; Warburton, Warburton, \& Hertzman, 2012). Current literature suggests that children could benefit from an integrated system of early childhood education and care programs that acknowledges the learning and care needs of young children (Corter, Janmohamed, \& Pelletier, 2012; Pascal, 2009).

In 2010, the province of Ontario began implementation of the FullDay Early Learning - Kindergarten Program (FDK), a two-year kindergarten program for all 4- and 5-year-olds in Ontario (Pascal, 2009). A critical component of this program is the co-teaching structure, with one Ontario-certified teacher and one registered early childhood educator (ECE) who share responsibility for each kindergarten classroom. This blended staffing model was articulated as the preferred model to "add to the strengths of the professional preparation and skill sets of both teachers and ECEs" (Pascal, 2009, p. 33). This model followed investigations that indicated that "children benefit and staff satisfaction is enhanced" in full-day programs (Pascal, 2009, p. 33).

Full-day kindergarten programs can benefit children with respect to their holistic development, transition to the primary grades, and academic development (Early Childhood Learning Division, 2011; Pascal, 2009; Ryan \& Date, 2014). In addition, these programs provide universal opportunities for children and families to access quality early learning environments (Early Childhood Learning Division, 2011; Pascal, 2009; Ryan \& Date, 2014). However, early analysis of outcomes from Ontario's full-day kindergarten program indicate greater effects for students from low-income families but fewer benefits for children identified as having special needs (Janus, Duku, \& Schell, 2012; Vanderlee, Youmans, Peters, \& Easterbrook, 2012). These differential outcomes may be related to the way in which the program is delivered. One of the strategies to ensure high-quality programs for all children in the province was to implement a team teaching model with one teacher who is registered with the Ontario College of Teachers and one ECE who is registered with the Ontario College of Early Childhood Educators.

This model is key to the program design and is intended to address the structural issue of adult-to-child ratios and to improve the educational process (Kluczniok \& Roßbach, 2014). However, the model has an inherent power imbalance in the educator partnership. One factor in this imbalance is the difference between a teacher's and an ECE's qualifications. Kindergarten teachers are required to have an undergraduate degree and a minimum of one year of teacher education, and teachers have had a professional college since 1997 (Ontario College of Teachers, 2014). ECEs have either a two-year diploma or a four-year degree in early childhood education, and have a long history of working to identify themselves as a professional group. It was not until 2008 that the College of Early Childhood 
Educators was established in Ontario (Ontario College of Early Childhood Educators, 2014). In addition to qualification differences, teachers have historically worked independently in classrooms, whereas ECEs have often worked in collaboration with other ECEs in childcare settings.

The roles of the two types of professionals in the FDK teaching teams were intentional and are complementary. Teachers "have knowledge of the broader elementary curriculum, assessment, evaluation and reporting, and child development" (Ontario Ministry of Education, 2010a, para. 1). They evaluate children's developmental progress within the context of the program and provide progress reports to parents (Ontario Ministry of Education, 2010a), and they prepare children for the transition to grade 1 (Pascal, 2009). ECEs "have knowledge of early childhood development, observation and assessment. They bring a focus on age-appropriate program planning that promotes each child's physical, cognitive, language, emotional, social and creative development and well-being" (Ontario Ministry of Education, 2010b, para. 2). In addition to the ECE role the Ministry outlines, Pascal (2009) describes responsibility for implementing extended day activities and summer programming, as well as liaising with community partners. Although the roles and responsibilities of both professionals were outlined in the planning, in reality, the province did not implement many of the responsibilities of the ECEs. The extended childcare components are separate from the kindergarten program, and in many jurisdictions are delivered by third-party organizations. Summer programming and broader community engagement through child and family centres have not been adopted as school responsibilities.

This study investigated the partnerships between the ECEs and kindergarten teachers in the first years of implementation of the FDK program. We investigated the nature of the partnerships and possibilities for adapting the partnerships to better capitalize on the expertise and skills of both educators for the benefit of children in the program.

\section{Partnership and Collaboration in Early Childhood Education}

Co-teaching happens in childcare settings quite frequently. By contrast, teachers might collaborate with other teachers for the planning process, or with itinerant teachers or assistants, but prior to FDK it was not common for them to team-teach their classes. Dalli (2008) identifies collaboration as one of the core values of the professional identity of early childhood educators. However, collaboration is not necessarily a component of co-teaching and we cannot assume that a co-teaching relationship is collaborative. Rose's (2011) examination of collaborative relationships in early childhood settings found that shared goals and acting for the good of those goals rather than acting as individuals is critical to successful partnerships. She notes that there may be some level of professional self-sacrifice in order for collective goals to be realized, and this may need to happen on the part of the professional with more power (Rose, 2011).

Payler and Georgeson (2013) found that the institutions within which professionals work shape their professional identities. As a result of these identities, professionals vary in their ability to be flexible, reactive, and collaborative. Therefore, the "potency" of one's actions can be shaped by the social context. Because the FDK classroom is a new context for ECEs and teachers, it will take time for their potency to become evident and to be felt in the institution.

Studies of FDK programs have shown mixed results with effective team approaches. Finn and Pannozzo (2004) examined the presence of a teaching aide (which we might call an assistant) in the classroom as a factor in the efficacy of kindergarten programs. They found that the presence of teaching assistants was either a neutral or slightly negative contributor to outcomes. Although our study does not include teaching aides, it is interesting to note that the presence of a second adult in a classroom does not necessarily improve outcomes. Further studies are needed to understand how two trained educators might affect children's experience in early childhood settings.

\section{Efficacy of Co-teaching Models in Special Education}

Co-teaching, the practice of two professionals with varied expertise but with professional parity, has long been used as a model to bring special education teachers into classrooms (Scruggs, Mastropieri, \& McDuffie, 2007; Walsh, 2012). Thus, co-teaching as an education model has been researched primarily in relation to children in the special education system. The model was developed with the underlying premise that specialist teachers and general classroom teachers should work together in one classroom, drawing on the skills that each brings to support a diverse group of children. The advantage to this model is that students can access the expertise of both educators in one location and therefore do not miss out on the support afforded by one or the other professional.

Six approaches to co-teaching, first identified by Bauwens, Hourcade, and Friend (1989), are now widely accepted in the co-teaching 
literature. The six approaches are as follows: one teach/one assist; one teach/one observe; tag team; station or rotational teaching; alternative teaching; and parallel teaching (see Table 1 for definitions).

Table 1. Code Definitions and Examples Found in Observations

\begin{tabular}{|c|c|}
\hline Code & Definition \\
\hline One teach/one assist & $\begin{array}{l}\text { In this approach, one teacher instructs the class while the other teacher } \\
\text { manages behaviour or assists individual students as needed. This } \\
\text { approach is possible when both educators share little planning time } \\
\text { together. It is recommended that this approach is only used occasionally, } \\
\text { and that the two educators alternate in their roles. }\end{array}$ \\
\hline One teach/one observe & $\begin{array}{l}\text { In this approach, one individual (generally the stronger of the two } \\
\text { teachers in the content or subject being taught) handles all instruction } \\
\text { while the other teacher floats or observes the students. This approach } \\
\text { requires little joint planning and is seen as valuable when both educators } \\
\text { decide which student behaviours should be noted by the observer. }\end{array}$ \\
\hline Tag team & $\begin{array}{l}\text { In tag team teaching, both teachers plan and deliver instruction together, } \\
\text { with each teacher equally responsible for the material in the lesson and } \\
\text { for activities around the classroom. This can be scripted or spontaneous. } \\
\text { This approach can lead to educators trying innovative techniques in } \\
\text { their teaching and requires the greatest level of mutual trust between } \\
\text { educators. It is a challenging model for new co-teachers to attempt. }\end{array}$ \\
\hline Station teaching (rotational) & $\begin{array}{l}\text { In station teaching, each teacher plans and is responsible for a different } \\
\text { aspect of the lesson or for a different lesson entirely. There may also be } \\
\text { independent work provided for the students. Students are divided into } \\
\text { two or more groups depending on how many stations are available, and } \\
\text { students either travel from centre to centre or stay in one position while a } \\
\text { teacher or activity moves to the student group. }\end{array}$ \\
\hline Alternative teaching & $\begin{array}{l}\text { In alternative teaching, one teacher teaches the main lesson to a } \\
\text { larger group of students while the other teacher works with a smaller } \\
\text { group of students on an entirely different lesson. This approach can be } \\
\text { useful when some students need highly intensive instruction for various } \\
\text { reasons, and all students can benefit from lower teacher-student ratios. }\end{array}$ \\
\hline Parallel teaching & $\begin{array}{l}\text { In parallel teaching, the class is split in half and each teacher teaches } \\
\text { the same lesson to half the class. Students all receive the same material } \\
\text { and benefit from lower teacher-student ratios. This approach requires } \\
\text { coordination between educators when planning content, and both } \\
\text { educators must be qualified to teach the content. }\end{array}$ \\
\hline
\end{tabular}

Note: Definitions derived from Friend and Cook (2010), Cook and Friend, (1995), and Scruggs, Mastropieri, and McDuffie (2007).

Over the last two decades, many researchers have observed and examined co-teaching partnerships and practices. Results from these studies suggest that to maintain effective teaching practices, educator teams should attempt several approaches, and both team members should take on the different roles within each approach (Friend \& Cook, 2010).

While co-teaching has been in the literature for several decades, there are a limited number of studies on the efficacy of this model (e.g., Hanover Research, 2012; Murawski \& Swanson, 2001; Scruggs, Mastropieri, \& McDuffie, 2007; Walsh, 2012). Scruggs, Mastropieri, and McDuffie (2007), in a metasynthesis of qualitative studies on co-teaching, found that the one teach/one assist approach was most common in practice and the special education teacher was often subordinate in the team. They also found that both teachers and students, with and without disabilities, reported benefits of the co-teaching model. However, in Scruggs et al.'s study the benefits to students' academic and skill levels were not clear. By contrast, Walsh (2012), in a study of a school-district-wide implementation of a co-teaching model over a six-year period, found improvements on standardized reading and math scores. Our study used the co-teaching model 
developed in the special education literature to analyze the co-teaching practices of ECEs and teachers in FDK classrooms.

\section{Method}

Six elementary schools located in southern Ontario participated in the study. The schools are located within one school board, are publicly funded, and are under the jurisdiction of Ontario's Ministry of Education. At the time of the study, all schools were within the first two years of implementation of FDK. Of the ten classrooms represented in this study, nine were staffed by one certified teacher and one registered ECE. In the tenth class, one ECE worked with two certified teachers (one who taught in the morning and one in the afternoon in a job-share situation). Thus, a total of 10 classrooms in 6 schools participated in the study, with 11 teachers and 10 ECEs.

Many of the teachers had more experience working in the school setting than the ECEs, which is not surprising given that the ECE position in Ontario's kindergarten classrooms is new. However, all but one of the ECEs in this study had experience working with young children in childcare programs prior to working in FDK. Six ECEs had worked as substitute ECEs in FDK prior to being hired full time. Overall, the teachers had more years of experience than the ECEs, with the range for teachers being 5 to 26 years and for ECEs 1 to 15 years. The teachers all had undergraduate-level education with one teacher having a graduate degree. Nine of the ECEs had a two-year diploma, one had a three-year diploma, and two had bachelor's degrees.

\section{Procedure}

Ethical approval for this study was obtained by the researchers' university and through the school district board of education. Semistructured interviews were conducted with the 11 kindergarten teachers and 10 ECEs. During the interviews we asked for a general description of the educators and children in the class, a description of the educators' experience with implementing the new team model, and the educators' own beliefs about the program itself. In addition, we conducted two observations per classroom on two separate occasions (one in the morning and one in the afternoon). Examples from the observations were used to develop the definitions of each co-teaching approach as described in Table 2 below.

Table 2. Examples of Co-teaching Approaches Found in Observations

\begin{tabular}{|l|l|}
\hline \multicolumn{1}{|c|}{ Code } & \multicolumn{1}{|c|}{ Example from observation } \\
\hline One teach/one assist & $\begin{array}{l}\text { Teacher tells ECE to keep children quiet. ECE responds that the } \\
\text { children were not talking. } \\
\text { Teacher hands picture cards to ECE to hold up while she reads a } \\
\text { book. } \\
\text { Teacher sets up a craft and tells ECE to supervise and make sure } \\
\text { children only put 4 to 8 legs on their spiders. }\end{array}$ \\
\hline One teach/one observe & $\begin{array}{l}\text { The teacher is doing a whole group lesson. The ECE sits at the back } \\
\text { and scans the group. }\end{array}$ \\
\hline Tag team & $\begin{array}{l}\text { During opening exercises at the front of the class with children on } \\
\text { the carpet, kindergarten teacher and ECE take turns singing songs, } \\
\text { asking about the date, and then they stand together to ask about the } \\
\text { life cycle of a butterfly. }\end{array}$ \\
\hline Station teaching (rotational) & $\begin{array}{l}\text { These examples largely consist of independent work on the part of } \\
\text { children. In one example, the ECE is working with children at one } \\
\text { centre to plant seeds. The kindergarten teacher is working on report } \\
\text { cards, with occasional interjections about children's behaviour. } \\
\text { The kindergarten teacher has a "work table" and the ECE circulates } \\
\text { to all the other centres. }\end{array}$ \\
\hline Alternative teaching & $\begin{array}{l}\text { The ECE enters the classroom and sees that a child is crying while } \\
\text { separating from her parent. The ECE takes her hand and sits with } \\
\text { her while the teacher begins to talk about the calendar and date. }\end{array}$ \\
\hline
\end{tabular}


Parallel teaching

The ECE takes junior kindergarten students into one room to work on activities designed by the teacher, while the teacher works on similar curriculum with senior kindergarten children in another room.

These definitions, along with the definitions in Table 1, were used to identify examples of co-teaching approaches in the interviews. Two researchers analyzed all of the interviews and a third researcher then reviewed the analysis and worked with the first two researchers to build consensus on the categorization of the interview statements into the co-teaching approaches.

\section{Findings}

Overall, the teacher and ECE interviews yielded similar results. While all approaches to co-teaching were described to some extent, the one teach/one assist approach was by far the most frequently described approach. It should be noted that there are limitations in quantifying the frequency of codes from interview data, since there is variation between subjects in terms of how much they talk and how many statements they use to describe a single phenomenon. However, Table 3 shows the overwhelming dominance of the one teach/one assist approach in the interviews. Descriptions provided by the participants, particularly of approaches other than the one teach/one assist approach, were sometimes described in hypothetical terms rather than as something that actually occurs in practice.

Table 3. Number of References to Co-Teaching Approaches During Interviews

\begin{tabular}{|l|c|c|c|}
\hline Co-teaching approach & Teacher interview & ECE interview & Total \\
\hline One teach/one assist & 126 & 125 & 251 \\
\hline Tag team & 27 & 6 & 33 \\
\hline Alternative teaching & 61 & 99 & 160 \\
\hline One teach/one observe & 23 & 10 & 33 \\
\hline Station teaching (rotational) & 46 & 20 & 66 \\
\hline Parallel teaching & 10 & 7 & 17 \\
\hline
\end{tabular}

One teach/one assist approach

While all of the teams described examples of the one teach/one assist approach, five teams described it as the main approach in their classrooms. Of these five teams, the teachers and ECEs agreed that this was the approach most commonly used. Rafaella, ${ }^{1}$ a teacher, reported that her understanding of ECE and teacher roles from the administration is that "I teach curriculum and they [ECEs] teach the domains, like social, emotional, cognitive. I want to combine those two together because they are meant to be working hand in hand." Rafaella reported that her role is to teach. She claims that because the ECEs do not get any planning time, "it is very challenging, [to] collaborate with Ambrosia, who is the ECE in the room." This lack of planning time for the ECE results in a one teach/one assist approach with Rafaella always taking the teaching role and Ambrosia taking the assist role because Rafaella does all the program planning. This co-teaching approach was echoed by Ambrosia, who believed that the "roles are not clear to a lot of teachers and principals. The teacher felt that behaviour management was not her job ... and that our job was to correct behaviours and do her prep work." Both Rafaella and Ambrosia gave some examples of the alternative teaching approach, but this may have been a way for the two educators to work independently of each other rather than to collaborate. Similarly, Lilibeth, a teacher, reported that

there's just not enough time for us to meet during the day, there's just no time. So I'll go in or I'll tell her the day before, "I'm working on this, and you'll do this; I'll do this." And then if she has a suggestion then fine, if not we just follow my model of what I set out to do and she's very willing. She just accepts what I said.

$1 \quad$ All names used in this article are pseudonyms. 
Dillon, the ECE working with Lilibeth, also described a one teach/one assist approach for the team: "In the end the last word is from the teacher. I can always say what I feel and she always takes that into consideration." The one teach/one assist pattern was evident, and the ECE deferred to the teacher as the expert. However, the educators in this team both felt that they got along well, and from the teacher's perspective, there was some give and take. The teacher described the benefits of having two adults in the classroom: "If there's a child you're having trouble with and you've tried everything, you [can ask the ECE:] 'can you try?'" Although this is an example of an attempt at a tag team approach, overall this team used a one teach/one assist approach the majority of the time and did not frequently alternate their roles.

Likewise, Heidi, a teacher, described a tag team approach, but it was limited to the planning process she did with other kindergarten teachers. This approach was not extended to her relationship with Emma, the ECE in the classroom. Heidi stated that her role as the teacher was

to implement the program based on curriculum, to team-teach with the other colleagues, and to keep my ECE abreast [of] what, on a daily basis, even a weekly basis, what we're planning to do. I already have the plan in motion from my colleagues and then I ask my ECE, "do you have anything to add?"

The one teach/one assist approach may be a result of teachers' and ECEs' understanding (or misunderstanding) of each other's profession. This is evidenced by Savannah, a teacher, who said that teachers and ECEs "come from two different schools, we come from obligations and legalities and they come from a different school of thought." She tells Austin, the ECE in the classroom, "this is what we are doing today, or as the periods go I'll say this is the next thing we are going to do." Austin also thought that there were differences between the two professions. He said, "The teachers, they've never done this. As ECEs we've worked like this [full-day with this age group], so we know. I think they've also learned from us." He reported that his role is to "assist the teacher" and that he is responsible for "behaviour management in the classroom, [making] sure that [the] children are playing nicely and listening to instructions and the rules ... and also just assisting the children one-on-one on cutting, pasting, anything that they need."

One interesting reflection on the interviews is that the educators' beliefs may not reflect their practice. In one case, Eve, a teacher, said that she believes she engages in a tag team approach, but examples throughout the interviews demonstrate that the one teach/one assist approach is dominant, with Eve doing the planning. However, Eve does combine outdoor play with another kindergarten classroom so that the children are supervised by the other kindergarten team and she and Sienna (the ECE) "get a half an hour where we can prep, and discuss and talk about things."

The interviews indicate that both teachers and ECEs believe that the one teach/one assist approach is the most prevalent approach in their co-teaching practice. The ECE is often responsible for behaviour guidance and supervision of play activities. This differentiated role could translate into an alternative teaching approach where each educator has a distinct but equally valued role, but at this stage of implementation, the alternative teaching approach is not prevalent.

\section{One teach/one observe approach}

Lena and Mia (teacher and ECE respectively) were the only team that described the one teach/one observe co-teaching approach. Lena had a special education background, and for this reason she was familiar with co-teaching approaches. The one teach/one observe approach was used frequently in this team, with both Lena and Mia observing and making notes. Lena said that as Mia gained experience, she would likely do more of the observations on her own. Lena acted as a mentor to Mia, and as such there were also examples of the one teach/one assist approach. Many of the observations that were an important part of this team's practice happened in centre activities, although these centres were also sites for the station teaching approach. In this partnership the one teach/one observe approach is dominant, but our interviews indicate that Lena and Mia also engaged in one teach/one assist and station teaching approaches as well, where the two educators were using stations to work with different children on different tasks. This team has the most variation in terms of the range of approaches identified. Both Lena and Mia focused primarily on child outcomes in their descriptions of their team's approach to teaching. The one teach/one observe approach was done primarily in the context of assessing and documenting students' work and not as part of instructional practice. 


\section{Tag team approach}

Of the 11 teams participating in this study, only one team described what could be defined as a tag team approach to teaching. Dana, the teacher, had transferred schools in order to work in the FDK program. Of the 11 teachers participating in the study, Dana had the strongest understanding of a tag team approach. She said, "All the decisions have to be made jointly. Of course both of us have our strengths and weaknesses, but I think we are really good at pairing our strengths." Dana and Misaki's ECE classroom is organized by centres, or stations, but the roles of the educators in this team do not indicate a primarily station teaching approach where they have separate responsibility for different stations. This is because they rotate throughout the room in a team teaching approach, sharing responsibility. Misaki, the ECE, also has a strong sense of collaboration. She said, "As a whole we pretty much do everything together. We share all of the responsibilities. So, you know, sometimes, I'll do one thing and Dana will do one thing. And then the next day we switch."

Dana said, "These are the students and this is their class, and I'm a teacher and yes that's great, and that's an ECE and that's great, but we're, like, we're here for the kids, right?" Her belief that "all the decisions have to be made jointly" helps to set the tone for a tag team approach.

\section{Alternative teaching approach}

The alternative co-teaching model was the dominant approach used by two of the 11 teams, but was represented in most of the interviews. Robin, a teacher, reported that she and Amber, her ECE partner, divide responsibilities, with Robin explicitly stating that she has responsibility for math and literacy. Amber viewed herself as the expert on play and discipline. Robin has had experience working in a co-teaching model, albeit with another teacher, and based on that experience she preferred an alternative teaching approach with distinct responsibilities for the curricular domains. She provided the following example to illustrate the approach:

I'll take this group of kids with me and we'll do the science while you [the ECE] focus on the reading assessment with this group of kids. Or, during reading centres, how about you [the ECE] take these three kids and you do three kids at a time and rotate?

The alternative teaching approach is evident when one professional takes the lead in the class and the other focuses on a small group of children for more intensive instruction.

\section{Parallel teaching approach}

Of the 11 teams, only one team described a parallel approach to teaching, where the class is split in half and each teaches the same lesson to their group of children. In this partnership, Chelsea, the teacher, clearly dominated the partnership. Chelsea did not agree with the full-day kindergarten model. She said:

They use the word team a lot, but clearly it is not a team. It's only a team from 9:00 to 3:30 and the fact that we're both in the same room and we're both working with children. But, aside from that, the planning, the trying to decide how we want this program to look, there's virtually no connection.

Chelsea shared that she does $100 \%$ of the planning, completes all the children's assessments, and is responsible for reporting. She stated that she "absolutely [does] not" work together with Alexis, the ECE, and she believes this is a consequence of undefined ECE roles and responsibilities. She says, "It's still not clear. The role of the ECE was never clearly defined from the start. It still hasn't been defined." In parallel teaching, the students are divided into two groups and each educator teaches a group. This parallel teaching approach involves Alexis carrying out a plan that has been developed by Chelsea.

\section{Discussion}

A range of co-teaching practices was described in the interviews. However, most of these practices were not described as being a regular part of the daily routine. The interviews indicate that both teachers and ECEs believe the one teach/one assist approach is the most prevalent in their co-teaching practice. The ECE is often responsible for behaviour guidance and supervision of play activities, while the teacher has the management role and defines the lesson plans. This differentiated role could translate into an alternative teaching 
approach where each educator has a distinct but equally valued role. However, at this stage of implementation, the alternative teaching approach is not prevalent.

Both teachers and ECEs were unclear about their roles in the classroom, and they described this as an important influence on their co-teaching partnership. Many of the references throughout the interviews to a tag team approach were actually hypothetical (i.e., this is what they think they are supposed to do), but the concrete examples described illustrate the one teach/one assist approach as predominant. All of the classrooms we observed were organized with centre-based activities; therefore, there is the possibility for the station teaching approach to occur. However, the observations indicate that few of the educators use this type of classroom organization as an opportunity to circulate and divide teaching duties.

The parallel teaching approach in this study was an example of how one team that was not functioning well was dividing their work so that they did not have to interact. However, in a high-functioning team, this approach could be effective, with each educator having responsibility for a distinct group of children while working on the same activities and being able to also work on separate tasks. Similarly, the alternative teaching approach, where each teacher is responsible for distinct activities, would allow at least some of the planning to be done independently.

Although the efficacy of co-teaching has yet to be established in empirical studies of the model (Hanover Research, 2012), qualitative studies have identified factors that educators believe are helpful in co-teaching. These include administrative support, planning time, training, and compatibility of the team members (Scruggs, Mastropieri, \& McDuffie, 2007). Most educators in this study identified planning time and professional development as critical to the co-teaching model, with varying degrees of administrative support for their work. For both teachers and ECEs, the power dynamics in their relationships are important. In order for both educators to be contributors and for the children to be beneficiaries of the expertise of the educators, the relationship requires respect, communication, and, above all, parity in the partnership (Scruggs, et al., 2007). For Moss (2013), fostering the partners to first develop a shared understanding of the educational goals involved with the emphasis on how the child learns means that both ECEs and teachers would need to work to combine their respective areas of expertise and knowledge and develop pedagogical practices that are their own. There were indications in this study to suggest that additional partnership supports would help with continued growth in the partner relationships.

The co-teaching model provides a framework to both teach educators alternate ways to work in partnerships, and to train teachers and ECEs in team approaches to support better implementation of the team teaching policy. The findings from this study indicate that there is potential to expand the repertoire of co-teaching practices between teachers and ECEs. The co-teaching practices explored in this study are adapted from special education models, but future research could explore models unique to kindergarten classrooms. In addition, future research should explore the effects of FDK educator partnerships on children's experiences in the classroom.

In summary, the following recommendations are made based on the findings of this study:

1. Co-teaching educators should reflect on their roles and relationship to better understand how they function as a team.

2. Co-teaching teams should expand their practice to include other co-teaching strategies. In this study, alternative teaching and parallel teaching were identified as potentially valuable approaches in kindergarten classrooms.

3. Clarification and support for acceptable roles from administration would allow a broader interpretation of how these teams can work together.

4. Planning time and professional development were identified by both teachers and ECEs as necessary for co-teaching. It is therefore recommended that these be addressed through administration and leadership.

While the partnership between teachers and ECEs is relatively new, some teams have now been in place for approximately 5 years. Now that the FDK implementation is complete, it is important to ensure ongoing support for these teams and to value the contribution of both educators. These recommendations provide opportunities to promote and improve the partnership and expand the ways in which these professionals are working together.

Acknowledgements: We would like to acknowledge Angela Lenis for her assistance in data analysis and preparation of this manuscript. 


\section{References}

Bauwens, J., Hourcade, J. J., \& Friend, M. (1989). Cooperative teaching: A model for general and special education integration. Remedial and Special Education, 10(2), 17-22.

Cook, L., \& Friend, M. (1995). Co-teaching: Guidelines for creating effective practices. Focus on Exceptional Children, 28(3), 1-25.

Corter, C., Janmohamed, Z., \& Pelletier, J. (2012). Toronto first duty: Phase 3 report. Retrieved from: http://www1.toronto.ca/City Of Toronto/Children's Services/Divisional Profile/Past Projects/firstduty/tfd_phase3report.pdf

Dalli, C. (2008). Pedagogy, knowledge and collaboration: Towards a ground-up perspective on professionalism. European Early Childhood Education Research Journal, 16(2), 171-185.

Early Childhood Learning Agency. (2009, April). Expanding early learning in British Columbia for children aged 3-5. Retrieved from: http://www2.gov.bc.ca/gov/DownloadAsset?assetId=4786368C12444A709CC845702C89D75D

Early Childhood Learning Division. (2011). Developing a provincial early childhood learning strategy. Retrieved from: http://www. ed.gov.nl.ca/edu/earlychildhood/literature_review.pdf

Finn, J., \& Pannozzo, G. (2004). Classroom organization and student behavior in kindergarten. Journal of Educational Research, 98(2), 79-91.

Flanagan, K. (2011). PEI early learning framework: Relationships, environments, experiences. Retrieved from: http://www.gov.pe.ca/ eecd/eecd_EYFrWrk_Full.pdf

Friend, M., \& Cook, L. (2010). Interactions: Collaboration skills for school professionals. Old Tappan, NJ: Pearson Education.

Hanover Research. (2012). The effectiveness of the co-teaching model: Literature review. Washington, DC: Author.

Janus, M., Duku, E., \& Schell, A. (2012). The full-day kindergarten early learning program final report. Hamilton, ON: Offord Centre for Child Studies, McMaster University.

Kluczniok, K., \& Roßbach, H. (2014). Conceptions of educational quality for kindergartens. Z Erziehungswiss, 17, 145-158.

Moss, P. (Ed.) (2013). Early childhood and compulsory education: Reconceptualising the relationship. Abingdon, England: Routledge.

Murawski, W. W., \& Swanson, H. L. (2001). A meta-analysis of co-teaching research: Where are the data? Remedial and Special Education, 22(5), 258-267.

Ontario College of Early Childhood Educators. (2014). History of the college. Retrieved from: https://www.college-ece.ca/en/AboutUs/ Pages/History-.aspx

Ontario College of Teachers. (2014). The ethical standards for the teaching profession. Retrieved from: http://www.oct.ca/-/media/PDF/ Standards Poster/standards_flyer_e.pdf

Ontario Ministry of Education. (2010a). Full-day kindergarten: Who is working in the classroom-Complementary skills. Retrieved from: http://www.edu.gov.on.ca/kindergarten/whoisworkingintheclassroom.html

Ontario Ministry of Education. (2010b). The full-day early learning kindergarten program (draft version) Retrieved from: https://www. edu.gov.on.ca/eng/curriculum/elementary/kindergarten_english_june3.pdf

Pascal, C. (2009). With our best future in mind: Implementing early learning in Ontario. Toronto, ON: Queen's Printers of Ontario.

Payler, J. K., \& Georgeson, J. (2013). Personal action potency: Early years practitioners participating in interprofessional practice in 
early years settings. International Journal of Early Years Education, 21(1), 39-55.

Rose, J. (2011). Dilemmas of inter-professional collaboration: Can they be resolved? Children \& Society, 25(2), $151-163$.

Ryan, T., \& Date, G. (2014). Reforming Ontario early learning: A review. Education 3-13: International Journal of Primary, Elementary, and Early Years Education, 42(1), 101-115.

Scruggs, T. E., Mastropieri, M. A., \& McDuffie, K. A. (2007). Co-teaching in inclusive classrooms: A meta-synthesis of qualitative research. Exceptional Children, 73(4), 392-416.

Vanderlee, M., Youmans, S., Peters, R., \& Easterbrook, J. (2012). Final report: Evaluation of the implementation of the Ontario full-day early learning kindergarten program. Retrieved from: http://www.edu.gov.on.ca

Walsh, J. M. (2012). Co-teaching as a school system wide strategy for continuous improvement. Preventing School Failure: Alternative Education for Children and Youth, 56(1), 29-36.

Warburton, W. P., Warburton, R. N., \& Hertzman, C. (2012). Does full-day kindergarten help kids? Canadian Public Policy, 38(4), 591-603. 